\title{
Téoros
}

Revue de recherche en tourisme

\section{La distribution du produit touristique}

\section{Louis Jolin}

Volume 9, numéro 3, novembre 1990

La distribution du produit touristique

URI : https://id.erudit.org/iderudit/1079881ar

DOI : https://doi.org/10.7202/1079881ar

Aller au sommaire du numéro

Éditeur(s)

Université du Québec à Montréal

ISSN

0712-8657 (imprimé)

1923-2705 (numérique)

Découvrir la revue

Citer ce document

Jolin, L. (1990). La distribution du produit touristique. Téoros, 9(3), 2-2.

https://doi.org/10.7202/1079881ar d'utilisation que vous pouvez consulter en ligne.

https://apropos.erudit.org/fr/usagers/politique-dutilisation/ 


\section{Présentation}

Louis Jolin

\section{La distribution du produit touristique}

La revue Téoros est heureuse de consacrer le présent numéro à cet aspect essentiel du système touristique que constitue la distribution du produit et du service touristiques. Ona pris conscience ces dernières années -à juste titre d'ailleurs -de l'importance de créer un bon produit touristique capable d'affronter la concurrence internationale, mais encore faut-il que ce produit se rende jusqu'au consommateur!

I/ existe plusieurs réseaux de distribution, parfois concurrents, parfois complémentaires: les réseaux d'agences de voyages, ceux mis en place directement par les prestataires de services avec l'aide de centrales de réservations, celui découlant de la télématique grand public.

Les réseaux de distribution sont changeants: ils sont pénétrés par les nouvelles technologies d'information, ils doivent composer avec les rapports de force au sein du système touristique, la création de grands blocs économiques à l'échelle de la planète n'est pas sans créer de profonds remous jusque dans le domaine de la distribution du produit touristique.

Nouvelles technologies, bouleversements géo-politiques, vive concurrence sur les marchés touristiques vont influencer le développement de la distribution. Les auteurs de ce numéro ont tenté de cerner ces influences et de dégager les enjeux pour l'avenir.

Si Paul Simier rappelle l'importance de la distribution du produit touristique dans ses diverses composantes tout en présentant l'agent de voyages comme "l'ultime maillon", Michel Langlois fait ressortir le glissement de leadership dans le tourisme d'affaires: des transporteurs aériens aux agences de voyages. Maire-Claire Louillet se met du point de vue d'un prestataire de services et analyse les choix qui s'offrent à une grande compagnie hôteliere. Deux articles touchent directement à l'apport de l'informatique: Stanley Tremblay présente les trois phases du développement des systèmes de réservations informatisés: les systèmes des transporteurs aériens, ceux des hôteliers et maintenant ceux dits de destination; Louis Rome souligne l'essor et l'intérét de la télématique grand public pour la distribution du produit touristique: $n$ 'a-t-on pas creé un nouveau mot,

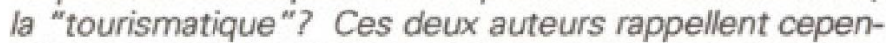
dant que ni l'informatique, ni la télématique ne tiendront lieu de stratégies de marketing et de promotion, mais que ces stratégies devront être modifiées pour tenir compte de l'apport inestimable des nouvelles technologies.

François Maurice se situe à un niveau continental et décrit les conséquences prévisibles de l'Acte unique européen sur l'industrie des voyages a forfait, tandis que de mon côté, máappuyant sur une analyse de la jurisprudence québécoise, j'aborde quelques aspects juridiques de la distribution, notamment ceux portant sur la responsabilité de plus en plus grande des grossistes et agents de voyages détaillants à l'égard du consommateur.

Pour compléter ce numéro, un article de Jean Stafford prolonge le précédent numéro consacré au marché américain par une analyse des cycles du tourisme americain au Québec. En plus des Chroniques réalisées par les étudiants et diplômés du module de gestion et intervention touristiques, nous introduisons une nouvelle rubrique EURINFO, sous la responsabilité de notre correspondant europeen André Hut Bonne lecture et les commentaires de nos lecteurs sont toujours fortement appréciés. $f$
UN INDEX DÉTAILLÉ ET DE NOUVEAUX TARIFS.

Pour souligner en 1991 la dixième année de la revue Téros, nous offrirons gratuitement à nos abonnés un index détaillé des articles parus depuis la création en 1982.

Cet index présentera les articles par ordre chronologique avec un bref résumé; il sera complété par un index "sujet" et un index "auteur". La parution de ce document de référence est prévue avec le vol 10, no 1 (mars 1991).

Pour affronter la hausse constante des coutts de production et pour continuer à offrir un produit de qualité, les tarifs augmenteront. A compter de 1991, ce qui inclut 1 'abonnement pour le volume 10 , le numéro à l'unité passera à $8,00 \$$, l'abonnement étudiant à $12,00 \$$, 1'abonnement régulier à 20,00 \$ et l'abonnement autres pays aे $25,00 \$$. Malgré ces hausses de prix, Téoros demeure une revue de recherche très accessible si on compare avec les prix des autres revues du même genre.

L.J. 